\title{
A natureza brasileira no poema $A$ Assumpção, de Frei Francisco de São Carlos.
}

\section{Gracinéa I. Oliveira, UFMG}

Resumo: O tema deste artigo é a representação da natureza brasileira no poema A Assumpção, de Frei Francisco de São Carlos. O poema é uma epopeia sacra, que narra a ascensão da Virgem Maria ao céu. Foi publicado, pela primeira vez, em 1819. Posteriormente teve apenas mais duas edições, ambas ainda no século XIX. O objetivo deste trabalho é apresentar uma pequena análise sobre a representação da natureza brasileira no poema, especificamente no Canto III. Serão abordados os aspectos inovadores e conservadores dessa temática, tendo como referência a tradição literária europeia e a brasileira, a que essa obra pertence.

Palavras-chave: natureza; Brasil; Frei Francisco de São Carlos.

O poema é uma epopeia sacra, que narra a assunção da Virgem Maria ao céu. Está dividido em oito cantos de versos decassílabos. Foi publicado, pela primeira vez, em 1819. Posteriormente teve apenas mais duas edições, ambas ainda no século XIX. Mas além dessas edições integrais, essa epopeia teve alguns trechos publicados, tanto no século XIX como no século XX, em livros que tratam sobre a literatura brasileira. Podem ser citados como exemplos o livro Résumé de l'histoire littéraire du Portugal, suivi du résumé de l'histoire littéraire du Brésil, de Ferdinand Denis ${ }^{1}$ e Capítulos de literatura colonial, de Sérgio Buarque de Holanda. ${ }^{2}$

Embora não seja nosso objetivo fazer uma biografia do autor, achamos importante contextualizar alguns dados do poeta, visto que o poema foi escrito há dois séculos e não é atualmente popular nem muito conhecido, mesmo nos meios acadêmicos: Frei Francisco de São Carlos nasceu em 1763 e morreu em 1829. Foi franciscano e pregador da Capela Real, no Rio de Janeiro, a convite de D. João VI. Deixou esse poema e alguns sermões. Quando pregou na Capela Real era conhecido como a Sereia do Púlpito. ${ }^{3}$

Mas apesar de não ser popular, esse poema é uma referência para a história da literatura brasileira. Chegamos a essa conclusão após a leitura do texto, a partir de sua fortuna crítica, que é considerável, ${ }^{4}$ e pelo fato de ele ser pelo menos citado na maioria das histórias da literatura do Brasil ${ }^{5}$. Diante do exposto, esta análise justifica-se na medida em que traz para a atualidade algumas reflexões sobre uma obra que muito contribuiu para a formação de nossa literatura.

A partir de um pequeno levantamento que fizemos da fortuna crítica do poema, ${ }^{6}$ chamou-nos a atenção o fato de a natureza brasileira ${ }^{7}$ ser um ponto de convergência entre todos os críticos, ou seja, todos que analisaram o poema comentaram esse tema, ora vendo como algo positivo, ora como algo negativo. No nosso entendimento, um tema não faz de um texto literário bom ou ruim. O que vai fazer a diferença é o modo como o poeta vai transformar aquele tema em uma obra de arte, ou seja, o artifício usado para 
tecer o tema na urdidura do texto. Mas se esse tema é notável em uma obra, é importante analisá-lo justamente para verificar como é sua trama na estrutura textual.

Antes, porém, de aprofundarmos nossa reflexão, é mister definirmos o conceito objeto de nosso trabalho: natureza. Entendemos por natureza tudo aquilo que é produzido no universo independentemente de ação refletida ou inconsciente. ${ }^{8}$ Iremos estreitar essa definição: natureza é entendida especificamente como elementos da paisagem natural.

Como estamos lidando com um conceito, pensamos que a melhor maneira de compreendê-lo é dentro do universo da cultura, ou melhor, dentro do universo discursivo. No caso de nossa análise, a natureza está em um domínio discursivo mais restrito: o literário. E é nessa esfera discursiva que analisaremos o papel da natureza do Brasil dentro desse poema.

Na epopeia A Assumpção a natureza brasileira vai aparecer em três cantos: no primeiro, no terceiro e no sexto. Mas, neste trabalho, por questões de espaço, iremos analisar a presença de elementos da natureza do Brasil apenas no terceiro canto, que trata da descrição do paraíso. Embora estejamos analisando a natureza do Brasil, é mister informarmos que, nesse canto, estão presentes também elementos da natureza de outras regiões, mas não serão comentados por fugirem ao nosso escopo. No terceiro canto, a natureza é descrita como mãe singela e nobre, que sempre é superior à arte na beleza e na perfeição:

\section{Canto III}

Ha no seio do Immenso huma paragem

Escondida aos mortaes; do Ceo imagem,

Lugar Santo, ditozo, sem pezares,

Onde os prazeres giram a milhares.

Habitação da paz, solar do rizo,

E com razão chamado Paraizo.

Não adulão a vista nestes prados

Arvoredos por ordem alinhados:

Nem marmoreas columnas Soberanas

De varias ordens gregas, ou Toscanas.

Nem maquinas hydraulicas, que as puras

Aguas deitão por varias mil figuras.

(...)

O amarello Ipé, tão lizonjeiro

Nas ribeiras do placido Janeiro:

Prezado berço meu, que fez a sorte

Do aurifero Brazil o centro, e a Corte

(...)

Vós mesmo, que a pezar da grão carreira

De seclos desaseis, vista fagueira

Ao Macedonio destes, ó immensos

Babilonios vergeis, no ar suspensos;

Vós sois brinco infantil, sois mero rizo,

Á vista deste illustre Paraizo 
Risco do Arquitector, que sem compaço

Curva linha traçou no ethereo espaço.

Feliz habitação, se cá no mundo,

Ou se fora do Ceo, painel jocundo

Podesse haver da Bemaventurança;

Tu foras copia só, só semelhança.

(...)

Doirados tectos, pavilhões custozos,

Tambem cobrem suspiros amargozos.

Ornára a lapa a madre natureza

De nobre gosto, mas com singeleza. ${ }^{9}$

Como é possível perceber na leitura desse excerto, inicialmente é dado a conhecer o lugar em que está localizado o paraíso: na imensidão do espaço, em um local vedado aos mortais. Em páginas seguintes, essa informação é retomada e o paraíso é um "risco do Arquiteto que curva linha traçou no espaço etéreo". Logo em seguida, o clima paradisíaco é descrito e, retomando antigas tradições, é o da eterna primavera; porém como há frutos nesse éden, a primavera está entrelaçada com o outono. Mas se a ideia da eterna primavera é retomada, a simetria clássica não aparece. Após situar o paraíso, comentar seu clima, a frescura e o verdor constantes, a descrição da paisagem paradisíaca não obedece a nenhum alinhamento. Não é possível saber se o local descrito refere-se a algum lugar no centro, na lateral, junto à entrada ou à saída do paraíso. As descrições sucedem-se sem seguir nenhuma linha ou curva: a visão não é mais panorâmica, é como a de um explorador que pela primeira vez adentra um lugar. A localização espacial das partes descritas é informada através de advérbios como "aqui", "acolá", etc. que não ajudam muito a situar tais espaços, já que o ponto de referência desses advérbios é o do locutor, ou seja, daquele que fala, não do leitor. Além disso, a presença de tais advérbios aumenta a subjetividade do texto. Esse emaranhado, que mais se parece com as incultas brenhas tropicais, é anunciado pelo poeta ${ }^{10}$, ainda na primeira página do terceiro canto:

Não adulão a vista nestes prados

Arvoredos por ordem alinhados:

Nem marmoreas columnas Soberanas

De varias ordens Gregas, ou Toscanas.

Nem maquinas hydraulicas, que as puras

Aguas deitão por varias mil figuras.

Só reina a natural simplicidade,

Que excede sempre a arte em magestade. ${ }^{11}$

Após tal explanação, o poeta solicita à Musa que adoce seus versos assim como os frutos que ele pintará. Nesse quadro ele junta a frutos de várias localidades, frutas consideradas típicas do Brasil como, por exemplo, a banana e o maracujá:

Dos bananais espessos arranjadas

Lourejão suas filhas; aguçando

$\mathrm{O}$ apetite, e os olhos afagando.

Dos folhudos festões estão pendentes, 
Pelo tronco trepando, os recendentes

Fructos da agreste flor, quadro imitante, ${ }^{12}$

Do martyrio, e paixão de hum Deos amante. ${ }^{13}$

Após descrever as frutas, o poeta comenta sobre os bosques e seus aromas. Posteriormente descreve os rios e os regatos que serpenteiam a paisagem paradisíaca. Não se esquece, também, das pedras preciosas e do ouro que tais águas carregam:

Rolando vem com ellas pelo fundo

Folhetas d'oiro; e tudo, quanto o mundo

Em preço tem; o rígido diamante,

O rubi, que da braza he semelhante;

A amathista, a chrysolita, a turqueza,

Lapidadas da propria natureza. ${ }^{14}$

Ao descrever os prados com suas flores, compara-os com a arte de bordar:

Assim como na seda, ou rica tella,

A agulha brinca da gentil donzella;

Tecendo com mil fios e mil cores

Primorozos padroens, varios lavores;

Tal era destes prados a pintura,

Que das agoas recebem a frescura. ${ }^{15}$

Após descrever as flores, o poeta se atenta aos pássaros. Também nessa parte, elementos da natureza brasílica aparecem, como é possível perceber nestes versos extremamente bucólicos, que pintam um quadro com perfeição:

Curvada com seo pezo, sobre a espiga

Ja loira do arrozal, a doce intriga

Modula o coleirinho, e lá do ramo

Da aroeira responde o gaturamo. ${ }^{16}$

A paisagem está bem construída nesse quarteto: cada verso contém uma cena que se prolonga até o verso seguinte através do enjambement: no primeiro verso, a imagem da espiga curvada devido ao peso do passarinho prolonga-se até o verso seguinte, em que é especificado que se trata de uma espiga de arroz. Nesse segundo verso é introduzida a imagem do passarinho cantando, que se prolonga até o terceiro verso, em que é especificado que se trata do coleirinho. Nesse terceiro verso, há outra imagem: a do ramo, que se prolonga até o quarto verso, em que se especifica que se trata da aroeira sobre a qual está outro pássaro: o gaturamo. Em outras palavras: julgamos perfeitos os quatro versos porque juntos criam um recorte, um quadro em que está "pintada" belamente uma cena bucólica.

Após a descrição da paisagem física, a ideia do paraíso como lugar aprazível é reforçada pelo comentário sobre a ausência de paixões, crimes, guerras e doenças nesse lugar edênico. Os anjos tutelares têm a missão de dissipar qualquer pesar que possa quebrar a tranquilidade do local. 
Também não podia faltar a Árvore da Inocência. Nela estão os dons que o céu dá aos inocentes: a graça, os sonhos, a alegria pura, a consciência e a paz. Esse paraíso é um local habitado não apenas por pássaros e anjos, mas também pelos santos Enoc e Elias que recebem a Virgem Maria.

Essa temática, mais especificamente, essa ideia de natureza como locus amoenus perpassa o universo discursivo literário ocidental. E levando em consideração esse universo, verificamos ser possível fazer duas leituras desse tema nessa obra: tradição e inovação.

É tradição porque, como já dissemos, a representação da natureza em um poema não é algo novo na literatura do ocidente. Esse tema aparece em textos literários da Época Clássica à época atual. Da paisagem de Homero, adotaram os poetas posteriores vários motivos, sólidos remanescentes de uma vasta cadeia tradicional: o lugar encantado da eterna primavera como cenário da vida bem-aventurada depois da morte; amável nesga da natureza, reunindo árvores, fontes e relvas, etc. ${ }^{17}$ E é dessa maneira amena (e não podia ser de outra, visto que se trata da descrição do paraíso) que a natureza aparece no poema de São Carlos, como podemos perceber nos seguintes versos:

Acola se entrelaça, como a héra

Co' rico Outono a olente primavera,

Frescos sempre os matizes da campanha

De perenne verdor, de graça estranha. ${ }^{18}$

Já na Idade Média, de acordo com Curtius, ${ }^{19}$ as descrições da natureza não traduziam a realidade. Por isso elas só podem ser bem interpretadas à luz de uma sólida tradição literária, visto que um poeta podia colocar, por exemplo, em uma descrição de uma paisagem nórdica, uma oliveira - árvore típica do Mediterrâneo. E foi seguindo essa tradição que poetas cristãos medievais aproveitaram a descrição dos Campos Elísios de Virgílio e a transformaram no paraíso cristão, acrescentando apenas as árvores frutíferas, imprescindíveis devido ao fruto proibido. ${ }^{20}$

Como exemplo (não medieval, mas do século XVII), podemos citar um trecho da descrição do paraíso de Milton, poema de publicação anterior a A Assumpção, e com o qual este mantém certa intertextualidade:

Visitando, com gosto e odor de néctar,

Por baixo de pendentes sombras gratas,

Todas as plantas, dando vida às flores

Que o sacrossanto Paraíso enfeitam,

Ali dispostas, não como esmerada

A arte as regula em detalhadas vistas,

Porém como a singela Natureza

As derramou com multidão profusa

Nos outeiros, nos vales, nas planícies,

Quer onde o Sol, em todo o giro diurno,

De luz e de calor os campos enche-

Quer onde a sombra de contíguas ramas

Lindos passeios ao mei'-dia tolda

(...) 
Aqui, formando deleitosas ruas,

Sempre florentes árvores destilam

Preciosas gomas, bálsamos cheirosos;

Brilham de outras ali pendentes frutos

De casca de ouro, de sabor insigne,

Realizando-se ali, ali somente,

Quanto as Hespérias fábulas divulgam. ${ }^{21}$

$\mathrm{Na}$ tradição portuguesa, o tema da natureza também aparece em muitas obras como, por exemplo, no episódio da Ilha dos Amores, nos Lusíadas, de Camões.

Além dessa tradição europeia, a representação da natureza manifesta-se também nas obras literárias produzidas no Brasil colônia, antes do poema de São Carlos. Para ilustrar, podemos citar alguns nomes do cânone nacional, como Santa Rita Durão, ${ }^{22}$ Botelho de Oliveira, ${ }^{23}$ Basílio da Gama ${ }^{24}$ e Itaparica. ${ }^{25}$ E não é qualquer natureza que é representada nessas obras, mas a da então colônia brasileira. Tendo como fio condutor esse tema - natureza do Brasil - podemos afirmar que houve uma tradição literária na colônia desde os primórdios, embora muitos estudiosos como Magalhães, ${ }^{26}$ Sodré, ${ }^{27}$ entre outros neguem tal tradição. Alguns desses pesquisadores, como Romero, ${ }^{28}$ Sodré, ${ }^{29}$ Coutinho ${ }^{30}$ afirmam que a literatura aqui produzida na época colonial era tão somente cópia da literatura europeia, ou seja, não era original. Mas, para nós, é extremamente complicado falar em originalidade no universo literário. O tópos natureza, por exemplo, foi retomado durante vários séculos na literatura ocidental, como é possível verificar nos estudos de Curtius ${ }^{31}$ sobre a literatura européia na Idade Média. Além disso, esse tema foi continuamente retomado na modernidade e na contemporaneidade. No caso específico da literatura brasileira e da produzida no Brasil antes da independência política, o que se percebe é um olhar diferente para a natureza, olhar esse que introduz novos motivos para esse tópos da antiga tradição literária ocidental. Sendo assim, o que para esses estudiosos era falta de originalidade, para nós, é intertextualidade. E essa intertextualidade mostra uma tradição literária que começava a se formar na então colônia, mas que mantinha diálogo com a tradição europeia. Entendemos que a natureza exótica do norte ao sul da Colônia e a língua portuguesa serviram de elo para a produção literária que aqui se fez na época, embora fosse grande o analfabetismo no período e os parcos centros urbanos, nos quais eram produzidas as poucas obras literárias da época, não mantivessem um bom canal comunicativo devido as distâncias, à precariedade das estradas e dos meios de transportes. Para ilustrar nossa afirmativa referente à tradição, vejamos alguns trechos das obras que citamos, tendo como fio condutor a descrição do caju:

De várias cores são os cajus belos,

Uns são vermelhos, outros amarelos,

E como vários são nas várias cores,

Também se mostram vários nos sabores;

E criam a castanha,

Que é melhor que a de França, Itália, Espanha. ${ }^{32}$

Inumeráveis são os cajus belos,

Que estão dando prazer por rubicundos, 
Na cor também há muitos amarelos,

E uns, e outros ao gosto são jucundos;

E só bastava para apetecê-los

Serem além de doces tão fecundos,

Que em si têm a Brasílica castanha

Mais saborosa, que a que cria Espanha. ${ }^{33}$

Os cajus, á saude tão prestantes;

Huns amarellos, e outros encarnados,

Das gostozas castanhas coroados:

Talismans, que lhes deo a natureza,

Por não se fascinar tanta belleza, (...). ${ }^{34}$

Como podemos perceber nos trechos citados e como já havia percebido Sérgio Buarque de Holanda: ${ }^{35}$ São Carlos "segue as obras que the antecederam em tudo e principalmente onde traduz seu encantamento diante da paisagem natural brasileira, adotando a fórmula fixada entre nós a partir de Botelho de Oliveira". Essa prática de seguir os poetas antecessores era um fato comum e recorrente, algo que os poetas da América do Norte, por exemplo, também faziam.

É importante frisarmos que não houve ruptura em relação à Europa, levando-se em consideração o tema da natureza. $\mathrm{O}$ que houve foi uma continuidade, mas agregada de novos elementos, não pura cópia ou imitação. E uma obra que ilustra bem essa inovação dentro de um gênero clássico europeu é o poema $A$ Assumpção. Comentaremos as inovações que detectamos no canto terceiro dessa obra.

Considerando a descrição do paraíso dentro do universo literário ocidental, podemos estabelecer um continuum desde a Idade Média europeia até o século XVIII, no Brasil. Conforme dissemos anteriormente, a descrição do paraíso foi aproveitada da literatura clássica, com alguns acréscimos para adaptação ao mundo cristão. Com São Carlos, esse tópos ganha mais um elemento inovador: a natureza brasileira. E o poeta tinha consciência dessa inovação, já que no prefácio do poema justifica tal uso: "Na descripção do Paraizo, servi-me de algumas fructas, e aves Americanas: sendo tudo obras do mesmo Creador, tanto direito tem de ser cantado o rouxinol, como o colibrio, a pêra, como o ananaz". ${ }^{36}$

Além da natureza brasileira, há também outros aspectos inovadores no poema. Um desses aspectos foi comentado anteriormente: na descrição do paraíso não há simetria nem harmonia clássicas. $\mathrm{O}$ modo como são feitas as descrições estão mais próximas da poética romântica, visto que não é possível estabelecer nenhuma linha, curva ou simetria na sucessão das descrições. Os quadros seguem-se ao sabor do poeta, numa profusão de tema e de cores: não é possível visualizar um panorama geral do paraíso. Além disso, percebe-se que o local se sobrepõe ao universal, o lirismo se sobrepõe ao comedimento e há exaltação da inocência e da natureza. Embora alguns autores, como Sérgio Buarque de Holanda, vejam nessa epopeia reminiscências do barroco: "frei Francisco de São Carlos é, quase tanto quanto frei Manuel de Santa Maria, um retardatário do Seiscentismo e, com efeito, desde o canto I da Assunção torna-se visível seu intento de oferecer-nos uma espécie de apoteose barroca". ${ }^{37}$ Nós não partilhamos desse entendimento: considerando o tempo histórico uma espiral, não uma linha reta, admitimos que ecos de outras épocas possam aparecer em produções literárias posteriores, sem que isso possa ser 
caracterizado como passadismo ou adoção de antigas poéticas. Partindo desse pressuposto, entendemos que o uso de uma ou outra metáfora culta, de certas figuras (emblema, etc.) que aparecem na epopeia não façam dela uma obra barroca. Além disso, não percebemos no poema nenhum conflito entre o espiritual e o temporal, entre o místico e o terreno, paradoxos, etc. que possam ser caracterizados como resíduos seiscentistas. Para nós, quando o poeta se afasta do clássico, ele se aproxima do romantismo, melhor, ele é um precursor do romantismo no Brasil.

Outro aspecto inovador que detectamos no poema refere-se à maneira como a natureza brasileira é inserida na epopeia. Essa tentativa de introduzir a paisagem tropical em uma epopeia hagiológica já havia sido feita antes, mais especificamente no século XVIII, por Frei Manuel de Santa Maria Itaparica. Mas o poeta setecentista não conseguiu encaixar a pintura de sua terra natal (Ilha de Itaparica) na epopeia que trata sobre a vida de Santo Eustáquio. Frei Manuel de Itaparica ${ }^{38} \mathrm{fez}$ da descrição da Ilha de Itaparica um "apêndice" do poema sacro Eustachidos. Em outras palavras, a descrição da ilha de Itaparica não está dentro da narrativa épica, mas a acompanha - vem no final da epopeia. Está separada desta por um frontispício que anuncia a "descripçaõ / da; ilha de itaparica, / termo da cidade / da / BAHIA, / da qual se faz mençam / no canto quinto". ${ }^{39}$ Caberia a um outro poeta de tempo posterior - São Carlos - fazer tal manobra estrutural e inserir em uma epopeia hagiológica a paisagem brasileira.

Pelo exposto, percebemos que a natureza, especificamente a do Brasil, ocupa um lugar de destaque na epopeia sacra de São Carlos. A partir da análise desse tema, verificamos que há um diálogo deste poema com outras obras literárias que o antecederam, principalmente com as produzidas na Colônia, mas também com algumas produzidas na Europa.

Além de dar continuidade a uma tradição do mundo discursivo literário ocidental e local, o poeta inova ao colocar a paisagem tropical brasileira no paraíso, ao inserir tal paisagem dentro da narrativa épica e no modo como a descreve.

\begin{abstract}
The theme of this paper is the representation of the Brazilian nature in the poem "Psalms", by Friar Carlos Francisco. Such poem is a sacred epic that chronicles the rise of the Virgin Mary into heaven. Its first edition was released in 1819. Further, it had only two other editions, both still in the 19th century. The aim of this paper is to make a brief analysis on the representation of the Brazilian nature in said poem, specifically in its Chant III. Innovative and conservative aspects of this theme are addressed, using the European and the Brazilian literary tradition as a framework. This poem belongs to the latter category.
\end{abstract}

Keywords: nature; Brazil; Friar Francisco de São Carlos. 


\section{Referências Bibliográficas}

CANDIDO, Antonio. Formação da literatura brasileira: momentos decisivos. 7 ed. Belo Horizonte: Itatiaia, 1993.

COUTINHO, Afrânio. Literatura no Brasil. Rio de Janeiro: São José, 1955.

CURTIUS, Ernst Robert. Literatura européia e Idade Média latina. São Paulo: Edusp, 1996.

DENIS, Ferdinand. Résumé de l'histoire littéraire du Portugal, suivi du résumé de l'histoire littéraire du Brésil. Paris: Lecointe et Durey, Libraires: 1828. Disponível em: <http://gallica.bnf.fr/ark:/12148/bpt6k1410551.r=ferdinand+denis+br\%C3\%A9sil+littera ture.langPT $>$. Acesso em 03 jul.2012.

FERREIRA, Aurélio Buarque de Holanda. Novo Dicionário Eletrônico Aurélio versão 6.0.1. 4 ed. Positivo: 2008.

GAMA, Basílio da. O Uraguay. In: TEIXEIRA, Ivan. Obras poéticas de Basílio da Gama: ensaio e edição crítica. São Paulo: Edusp, 1996.

HOLANDA, Sérgio Buarque de. Capítulos de literatura colonial. São Paulo: Brasiliense, 2000.

ITAPARICA, Frei Frei Manuel de Santa Maria. Eustachidos: poema sacro, e tragicômico, em que se contèm a vida de $S$.to Eustachio martyr, chamado antes Placido, e de sua Mulher, e Filhos. [s.l: s.n.], [1769]. In: MIRANDA, José Américo. EUSTÁQUIDOS, de Frei Manuel de Santa Maria Itaparica: preparação de uma edição fidedigna, 2008. [Relatório de pesquisa].

MAGALHÃES, Gonçalves de. Discurso sobre a história da literatura do Brasil. In: COUTINHO, Afrânio. Caminhos do pensamento crítico. Rio de Janeiro: Americana, 1974.

MILTON, John. Paraíso perdido. São Paulo: Martin Claret, 2010.

MIRANDA, José Américo. EUSTÁQUIDOS, de Frei Manuel de Santa Maria Itaparica: preparação de uma edição fidedigna, 2008. [Relatório de pesquisa].

MOTA, Artur. História da literatura brasileira. São Paulo: Academia Paulista de Letras, 1978. (volume 03, tomo II).

OLIVEIRA, Gracinéa I. Reflexões sobre a recepção do poema A Assumpção, de Frei Francisco de São Carlos, 2012 [Ensaio ainda não publicado].

OLIVEIRA, Manuel Botelho de. Poesia completa: música do parnasso lira sacra. São Paulo: Martins Fontes, 2005. [Prefácio e organização do texto por Adma Muhana].

PINHEIRO, Fernandes. Estudo crítico. In: SÃO CARLOS, Frei Francisco. A Assumpção: poema composto em honra da Santa Virgem. Rio de Janeiro: Garnier, 1862. Disponível em:

$<$ http://books.google.com/books?id=7ZkCAAAAYAAJ\&printsec=frontcover\&hl=pt$\mathrm{BR} \&$ source $=\mathrm{gbs}$ ge_summary_r$\& \mathrm{cad}=0 \# \mathrm{v}=$ onepage $\& \mathrm{q} \& \mathrm{f}=\mathrm{false}>$. Acesso em 10 jun. 2011. 
ROMERO, Sílvio. História da literatura brasileira. 3 ed. Rio de Janeiro: [s.n], 1943 apud SODRÉ, Nelson Werneck. História da literatura brasileira: seus fundamentos econômicos. 6 ed. Rio de Janeiro: Civilização Brasileira, 1976.

SANTA RITA DURÃO, Frei José de. Caramurú: poema épico do descobrimento da Bahia. Bahia: Typographia de Serva e Comp., 1837.

SÃO CARLOS, Frei Francisco. A Assumpção: poema composto em honra da Santa Virgem. Rio de Janeiro: Garnier, 1862. Disponível em: $<$ http://books.google.com/books?id=7ZkCAAAAYAAJ\&printsec=frontcover\&hl=pt-

$\mathrm{BR} \&$ source $=\mathrm{gbs}$ ge_summary_r$\& \mathrm{cad}=0 \# \mathrm{v}=$ onepage $\& \mathrm{q} \& \mathrm{f}=$ false $>$. Acesso em 10 jun. 2011.

SODRÉ, Nelson Werneck. História da literatura brasileira: seus fundamentos econômicos. 6 ed. Rio de Janeiro: Civilização Brasileira, 1976.

VERÍSSIMO, José. História da literatura brasileira: de Bento Teixeira a Machado de Assis. 3. ed. Rio de Janeiro: Livraria José Olympio, 1954.

\section{Notas}

${ }^{1}$ DENIS, Résumé de l'histoire littéraire du Portugal, suivi du résumé de l'histoire littéraire du Brésil.

${ }^{2}$ HOLANDA, Capítulos de literatura colonial.

${ }^{3}$ PINHEIRO, Biographia, p. XIV.

${ }^{4}$ MOTA, Fr. Francisco de S. Carlos, p.286-287.

${ }^{5}$ VERÍSSIMO, História da literatura brasileira: de Bento Teixeira (1601) a Machado de Assis (1908). p.114-145.

${ }^{6}$ OLIVEIRA, Reflexões sobre a recepção do poema A Assumpção, de Frei Francisco de São Carlos.

${ }^{7}$ Embora esse poema tenha sido publicado em 1819, período em que o Brasil era Reino Unido de Portugal e Algarves, não iremos nos referir ao Brasil como Reino Unido, visto que há pesquisadores, como Candido (1993, p. 298), que afirmam que o poema tenha sido composto entre 1804 e 1809, ou seja, na maior parte deste período, o Brasil ainda era Colônia. O importante, para nossa análise, não é a condição política do Brasil, mas a presença dos elementos da paisagem do local hoje chamado Brasil nessa epopeia.

Outro fato que gostaríamos de comentar refere-se à expressão "natureza do Brasil" ou "natureza brasileira". Embora saibamos que natureza não tem nacionalidade, usamos essa expressão para designar elementos da paisagem típicos do Brasil ou que tradicionalmente são relacionados ao Brasil. Tais expressões são comuns em textos de alguns pesquisadores, como percebemos neste excerto: “... o ingênuo Frei Francisco promove a natureza brasileira a alturas inéditas, (...)” (CANDIDO, 1993, p.200 - grifo nosso).

${ }^{8}$ FERREIRA, Novo Dicionário Eletrônico Aurélio versão 6.0.1.

${ }^{9}$ SÃO CARLOS, A Assumpção: poema composto em honra da Santa Virgem, p.71-77; 81- 82 . 
${ }^{10}$ A palavra poeta, nesse caso e nos demais que se seguem, não se refere ao sujeito físico, ou seja, à pessoa Frei Francisco de São Carlos, mas sim ao eu lírico.

${ }^{11}$ SÃO CARLOS, A Assumpção: poema composto em honra da Santa Virgem, p.71-72.

12 Trata-se do maracujá, também conhecido como "flor da paixão".

${ }^{13}$ SÃO CARLOS, A Assumpção: poema composto em honra da Santa Virgem p.72-73.

${ }^{14}$ SÃO CARLOS, A Assumpção: poema composto em honra da Santa Virgem, p.75.

${ }^{15}$ SÃO CARLOS, A Assumpção: poema composto em honra da Santa Virgem, p.76.

${ }^{16}$ SÃO CARLOS, A Assumpção: poema composto em honra da Santa Virgem, p.77-78.

${ }^{17}$ CURTIUS, Literatura européia e Idade Média latina, p.245.

${ }^{18}$ SÃO CARLOS, A Assumpção: poema composto em honra da Santa Virgem, p.72.

${ }^{19}$ CURTIUS, Literatura européia e Idade Média latina, p. 241-243.

${ }^{20}$ CURTIUS, Literatura européia e Idade Média latina, p. 258.

${ }^{21}$ MILTON, Paraíso perdido, p.152-153

22 SANTA RITA DURÃO, Caramurú.

${ }^{23}$ OLIVEIRA, Silva à Ilha da Maré. A primeira edição desse livro é de 1705.

${ }^{24}$ GAMA, O Uraguay.

25 ITAPARICA, Eustachidos: poema sacro, e tragicômico, em que se contèm a vida de S.to Eustachio martyr, chamado antes Placido, e de sua Mulher, e Filhos.

${ }^{26}$ MAGALHÃES, Discurso sobre a história da literatura do Brasil.

${ }^{27}$ SODRÉ, História da literatura brasileira: seus fundamentos econômicos.

${ }^{28}$ ROMERO, História da literatura brasileira.

${ }^{29}$ SODRÉ, História da literatura brasileira: seus fundamentos econômicos.

${ }^{30}$ COUTINHO, Literatura no Brasil.

${ }^{31}$ CURTIUS, Literatura européia e Idade Média latina, p. 245.

32 OLIVEIRA, Poesia completa: música do parnasso lira sacra, p. 31 .

${ }^{33}$ ITAPARICA, Eustachidos: poema sacro, e tragicômico, em que se contèm a vida de S.to Eustachio martyr, chamado antes Placido, e de sua Mulher, e Filhos, p.54.

${ }^{34}$ SÃO CARLOS, A Assumpção: poema composto em honra da Santa Virgem, p.72.

${ }^{35}$ HOLANDA, Capítulos de literatura colonial, p.75.

${ }^{36}$ SÃO CARLOS, A Assumpção: poema composto em honra da Santa Virgem p.V-VI.

${ }^{37}$ HOLANDA, Capítulos de literatura colonial, p.68

${ }^{38}$ ITAPARICA, Eustachidos: poema sacro, e tragicômico, em que se contèm a vida de S.to Eustachio martyr, chamado antes Placido, e de sua Mulher, e Filhos.

${ }^{39}$ MIRANDA, Eustáquidos, de Frei Manuel de Santa Maria Itaparica: preparação de uma edição fidedigna, p.15. 